\title{
Requirement Engineering for Intelligent Vehicles at Safety Perspective
}

\author{
Madhusudan Singh \\ Yonsei Institute of Convergence Technology, Yonsei University, Songdo, Incheon, South Korea \\ Abstract
}

Abstract - In the coming years, transportation system will be revamped in a manner that there will be more intelligent and autonomous vehicle phenomenon around us such as smart cars, auto driving system, etc. Some of automotive industries are already producing smart cars. However, the main concern of this paper is on the infrastructure for intelligent vehicles, which can support such intelligent transportation. Current transportation system lacks proper infrastructure to support intelligent vehicles. Hence in this article, we have surveyed and analysed the current transportation system in developed and developing countries. In contrast, we are going to introduce secure intelligent transportation (roadside) infrastructure that is user centric (Driver, Autonomous driver etc.) for Intelligent vehicles. In this paper we present the basic requirements of safety engineering infrastructure of roadside infrastructure in ITS for Intelligent vehicles. Intelligent vehicles has network infrastructure to communicate with vehicle-to-vehicle (V-to-V), vehicle-to-infrastructure (V-to-I), lane correction system, and traffic information system etc. The Intelligent vehicle is a good model for learning demands of infrastructure for ITS process because the system having many use-cases and we must understand relationship between public institutions, people, companies in order to proceed ITS System.

Received on 13 June 2017; accepted on 03 August 2017; published on 20 December 2017

Keywords: Intelligent Vehicles; Requirement Engineering; ITS

Copyright (C) 2017 Madhusudan Singh, licensed to EAI. This is an open access article distributed under the terms of the Creative Commons Attribution license (http://creativecommons.org/licenses/by/3.0/), which permits unlimited use, distribution and reproduction in any medium so long as the original work is properly cited.

doi:10.4108/eai.20-12-2017.153496

\section{INTRODUCTION}

After starting full-scale vehicle life in the 1970s, society has required the development of transport system for safety and efficiency. Automotive industry has obtained not only accelerating industrialization but also expanding of living area. But, behind the scenes, social costs were increased by traffic accidents. To prevent these situations, we need a more advanced ITS system then the current scenario.

This paper presents the basic requirements of safety engineering infrastructure of roadside infrastructure in ITS for Intelligent vehicles. Intelligent vehicles has network infrastructure to communicate with vehicle-to-vehicle (V-to$\mathrm{V}$ ), vehicle-to-infrastructure (V-to-I), lane correction system, and traffic information system etc. The Intelligent vehicles has a good model for learning demands of infrastructure for ITS process because the system have a lot of use-cases and we must understand relationship between public institutions, people, companies in order to proceed ITS System.

This paper has organized into sections as follows: Section II provides problem in intelligent vehicles and their challenges in V-to-V communication system. Section III, provides the requirement specifications of safe and secure engineering design architecture. In the section IV, we discussed the novel safe and secure engineering model for intelligent vehicles. Finally, in the section V, we have concluded final remarks and impact of intelligent vehicles with the respect of social, technical and business.

Current ITS technique optimize traffic management and highway capacity by introducing spatial-temporal distribution of traffic flow to provide information through various media such as VMS, broadcast, internet, and etc. after ITS collects real-time traffic information through detection devices and CCTV on the highway in $2,804 \mathrm{~km}$ of 23 routes. However, republic of Korea has operated highway traffic management system, since public infrastructure investment planning group to the president introduced ITS in 1993 [7]. However, ITS infrastructure has to consider road, IT, and Vto- $\mathrm{V}$ communication such as shown in fig.2.

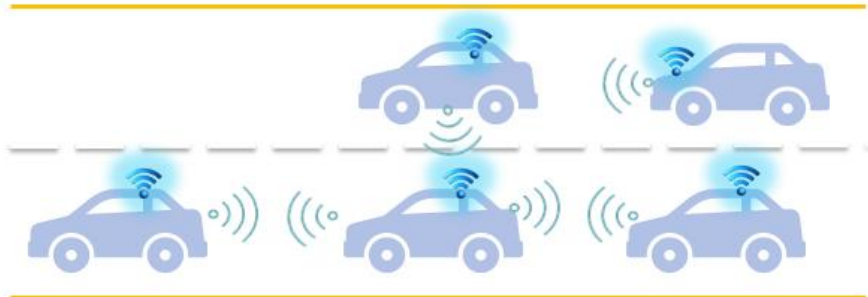

Fig.2. Vehicle-to-Vehicle communication system.

A. Current Infrastructure and Challenges in ITS

- Information content: There is no condition of information exchange type between road and vehicle Therefore we need to provide point-based traffic information (VMS-oriented) and indirect information such as ARS, Internet, etc.

- Communications: There is no demand control function for preventing excess capacity. Therefore Lack of traffic flow distributed technology of whole road in case of emergency, Lack of real-time sensing function in case of emergency, Lack of estimated function of traffic, condition when delaying.

- Security: Restrictive crackdown of unit point about Violator's vehicles which are the main culprit of big accident passive management systems such as use of manpower when road maintenance management (safety issue)

- Others : Interchange (IC) system that abnormally add to the ETC, Difficulty of differentiated Services about the ETC vehicle, Limited payment structure (prepaid), uniform way to settle the charges on IC system, Lack of velocity-based and high-tech traffic condition model, However, there is no information service for road manager.

EAI Endorsed Transactions on Smart Cities 
The basic requirements of intelligent transportation world such as intelligent transportation system, Infrastructure, smart vehicles, intelligent vehicles requirements and their challenges are given in fig. 3.

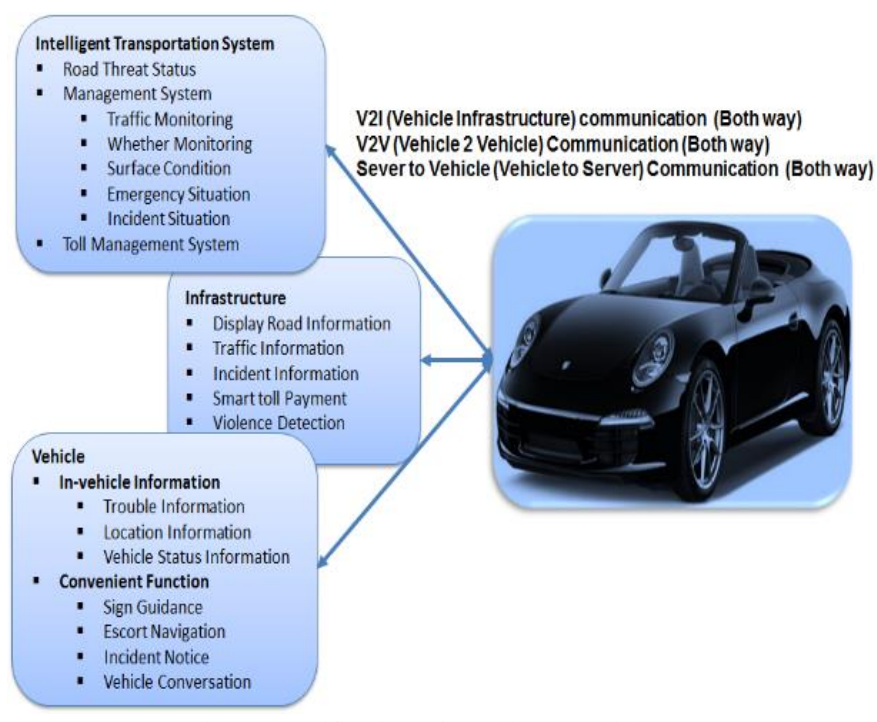

Fig. 3. Specification of Intelligent vehicles.

\section{ENGINEERING MODEL FOR SAFETY}

The overview infrastructure of a secure Intelligent vehicles in ITS has shown in fig. 4, where the communication tower collect the data such as traffic data, weather data on highway, car data on highway based on data of mobile device that mounted in the car, radio tower send data to main data normalization and event analyzers system. After the analysis of data, the information forwarded to the information storage cloud to mobile device again. Then mobile device provides user interfaces to check easier with input value of the driver (user).

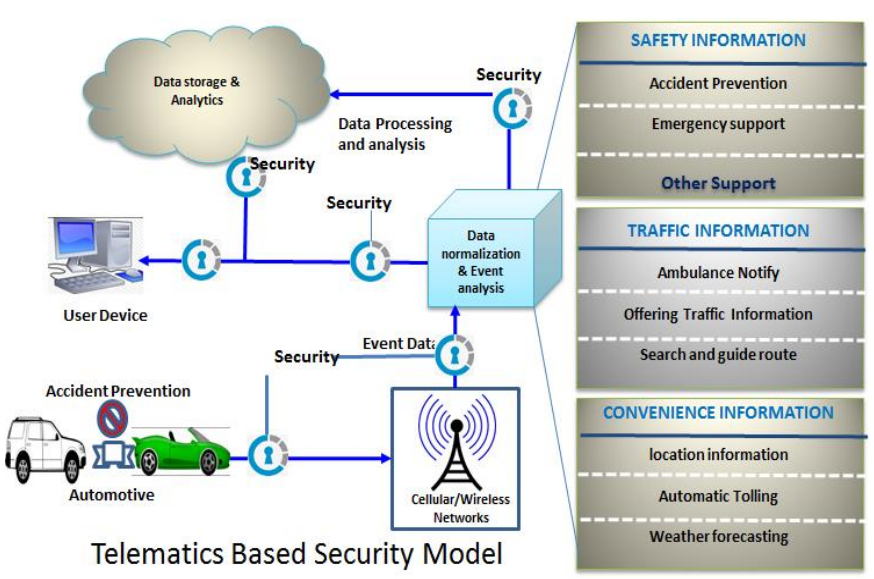

Fig. 4. Telematics based safe Intelligent vehicles.

The major requirements of the telematics based safe and intelligent vehicles system are required mainly four words of system which is as follows

- Subject roadside: The subject matter of the information system.
- System roadside information: Charge, traffic jam and so on.

- Usage Driver: The environment within which the planned system will operate.

- Network System: Driver who use the high-way, and stakeholder who related on the high-way system.

- System intelligent roadside: What the system does within its operational environment, what information it contains and what function it performs.

- Data management system: System manages all information related on smart high-way such as smarttolling, transfer information that make a more efficient system to driver.

A. Use case diagram of Engineering Modeling in ITS

Grasp related behavior between the driver and the smart highway group, we will find detailed in following Use case descriptions about the action run which order and what's related towards to each behavior. Based on these, we expect to get final goal of analysis the behavior and purpose of each sub-goal on goal based approach.

Table I has shown description of USE case of secure engineering design for intelligent vehicles.

TABLE I. USECASE DESCRIPITION OF SECURE ENGINEEIRNG

\begin{tabular}{|c|c|c|c|}
\hline $\begin{array}{c}\text { Use } \\
\text { Case }\end{array}$ & Name & Pre-Condition & Post -Condition \\
\hline UC1. & Smart-tolling & $\begin{array}{l}\text { Connected } \\
\text { successfully } \\
\text { between mobile } \\
\text { device in vehicle } \\
\text { and main system }\end{array}$ & $\begin{array}{l}\text { Calculate smart } \\
\text { highway toll by } \\
\text { minimizing } \\
\text { decrease of vehicle } \\
\text { speed }\end{array}$ \\
\hline UC2. & $\begin{array}{l}\text { Preventing of } \\
\text { car accident }\end{array}$ & $\begin{array}{l}\text { Network between } \\
\text { Terminal } \\
\text { Application and } \\
\text { Command Center } \\
\text { Application } \\
\text { always should be } \\
\text { maintained } \\
\text { All of users are } \\
\text { must enrolled in } \\
\text { Smart Highway's } \\
\text { member }\end{array}$ & $\begin{array}{l}\text { Prevention of car } \\
\text { accident's function } \\
\text { provide intelligence } \\
\text { information which } \\
\text { can prevent car } \\
\text { accident } \\
\text { integrating terminal } \\
\text { application's data } \\
\text { and sensor's data } \\
\text { using in smart } \\
\text { highway }\end{array}$ \\
\hline UC3. & $\begin{array}{l}\text { Supporting } \\
\text { information for } \\
\text { emergency and } \\
\text { disaster } \\
\text { situation }\end{array}$ & $\begin{array}{l}\text { Connected } \\
\text { successfully } \\
\text { between mobile } \\
\text { device in vehicle } \\
\text { and main system }\end{array}$ & $\begin{array}{l}\text { Improve efficiency } \\
\text { by checking } \\
\text { information that is } \\
\text { identified by sensor, } \\
\text { and it builds a } \\
\text { database }\end{array}$ \\
\hline UC4 & $\begin{array}{l}\text { Weather } \\
\text { forecast }\end{array}$ & $\begin{array}{l}\text { Connected } \\
\text { successfully } \\
\text { between mobile } \\
\text { device in vehicle } \\
\text { and main system }\end{array}$ & $\begin{array}{l}\text { To prevent } \\
\text { accidents due to bad } \\
\text { weather }\end{array}$ \\
\hline UC5 & $\begin{array}{l}\text { Urgent } \\
\text { Emergency } \\
\text { notify }\end{array}$ & $\begin{array}{l}\text { The emergency } \\
\text { vehicle enter the } \\
\text { smart highway, } \\
\text { and main system } \\
\text { detect the entry of } \\
\text { vehicle }\end{array}$ & $\begin{array}{ll}\text { Handle } & \text { the } \\
\text { emergency } & \\
\text { successfully, so } \\
\text { decrease threat } \\
\text { smart highway }\end{array}$ \\
\hline UC6 & $\begin{array}{l}\text { Using } \\
\text { additional } \\
\text { service in smart } \\
\text { highway }\end{array}$ & $\begin{array}{l}\text { Network between } \\
\text { Terminal } \\
\text { Application and } \\
\text { Command Center } \\
\text { Application } \\
\text { always should be } \\
\text { maintained }\end{array}$ & $\begin{array}{l}\text { Actor's } \\
\text { convenience and } \\
\text { satisfaction arise by } \\
\text { using additional } \\
\text { service in Smart } \\
\text { Highway }\end{array}$ \\
\hline
\end{tabular}




\section{IMPACT AND FINAL REMARKS}

In upcoming years transportations system will be completely modify. It will be more intelligent and autonomous vehicle around us such as smart car, auto driver, etc. Some of automotive industries already produce smart car. But our main concern about infrastructure of transportation system which support intelligent transportation. Current infrastructure will be not support intelligent transportation system. So, in this article, we are going to introduce secure intelligent transportation (roadside) infrastructure of user's (Driver, Autonomous driver etc.) point of view. It's called intelligent transportation infrastructure. The impact of intelligent vehicles in ITS will proved to be a break through on the existing infrastructure of transportation system. These are some of the following effects.

\section{A. Social Impact}

- Provide better and effective transportation life.

- Provide safe and rapid transit information service under high speed driving conditions.

- Satisfy the driver's driving service and improve the quality of life

- Provide traffic information service that fuses with telematics

- Provide continuous ITS service in time and space through expansion and linkage of existing ITS technologies

\section{B. Business Impact}

- Core technology pre-emption related to ITS service as next-generation growth power and synergy effect of technical

- By exporting developed technology, be more competitive in the world market and exploit a way out of export with all technology that need to build test bed

- Expect creating a ripple effect of related industry: have direct and indirect influence on widespread industry such as vehicle, wireless communication, mobile communication terminal, internet, $\mathrm{m}$ commerce and etc.

- Promote the national economy by reducing personnel and materiel cost in traffic congestion and traffic accidents that may occur in road under the goal of ITS technical development of 'accidentfree' and 'nonstop'

- Inducement the creation of new employment about spreading industry related to ITS: by invigorating the ITS services, promote domestic industry and induce the creation of new employment

\section{Technical Impact}

- In high-speed driving environment, guiding role of technology related to real-time DB processing technology development and middleware technology development

- Guarantee of technology caused by alliance of telematics services as part of the national policy and Intelligent Roadside infrastructure.

- Globally source technology secure caused by developing the domestic technology by designing the architecture related to developing a traffic monitoring and traffic information fusion technology under the high-speed traffic condition the domestic technology

\section{REFERENCES}

[1] D. Singh and M. Singh, "Internet of vehicles for smart and safe driving," 2015 International Conference on Connected Vehicles and Expo (ICCVE), Shenzhen, 2015, pp. 328-329.

[2] Z. Junping, W. Fei-Yue, W. Kunfeng, L. Wei-Hua, X. Xin and C. Cheng, "Data-Driven Intelligent Transportation Systems: Survey", IEEE Transactions on Intelligent Transportation Systems, vol. 12, no. 4, pp. 1624-1639, 2011.

[3] D. Singh and A. Alberti, "Developing NovaGenesis Architecture for Internet of Things Services: Observation, Challenges and ITMS Application", International Conference on ICT Convergence 2014.

[4] Woong Cho, Hyun-seo Oh, Byeong-joo Park, "Wireless Access Technologies for Smart Highway : Requirements and Preliminary Results", The Journal of the Institute of Internet, Broadcasting and Communication, Vol. 11, No. 2, pp.237-244, April, 2011.

[5] D. Singh, M. Singh, I. Singh and H. J. Lee, "Secure and reliable cloud networks for smart transportation services," 2015 17th International Conference on Advanced Communication Technology (ICACT), Seoul, 2015, pp. 358-362.

[6] Sujin Kwag, Sangsun Lee, "A Survey of V2X Communication Technologies and project", Journal of the Korea Society of Automotive Engineers, Vol. 33 No. 5, pp.24-31, May, 2011.

[7] Jung-Hoon Song, Jae-Jeong Lee, Seong-Ryul Kim, Jung-Joon Kim, Dae-Wha Seo, "Design of u-Transportation Communication System for Next-Generation ITS Services", The Journal of The Korea Institute of Intelligent Transport Systems, Vol. 12, No. 5, pp.61-72, October, 2013 